\title{
EVALUACIÓN SENSORIAL Y ANALÍTICA DE LA CALIDAD DE ACEITE DE OLIVA EXTRAVIRGEN
}

\author{
SENSORIAL AND ANALYTICAL EVALUATION OF THE \\ EXTRA-VIRGIN OIL QUALITY
}

\author{
Nelson Loyola López ${ }^{1}$; Roberto López Acevedo ${ }^{1}$; Carlos Acuña Carrasco ${ }^{1}$
}

\begin{abstract}
RESUMEN
El aceite de oliva extravirgen es extraído mecánicamente del fruto del Olivo (Olea europaea L.), por métodos de molturación, batido y centrifugación, agregando agua con la finalidad de facilitar la extracción del aceite contenido en la pulpa del fruto, y debe tener una acidez menor o igual al 0,8\% expresada en ácido oleico y una puntuación organoléptica menor o igual a 6,5 puntos, conservando así valiosos compuestos polifenólicos del fruto originario, y que le otorga una gran calidad, además de un excelente gusto y aroma, los que se traducen en su amargor y picor, por lo cual es necesario determinar la calidad del aceite nacional.

El presente estudio tuvo como objetivo evaluar el efecto de la adición de agua en el proceso de elaboración, sobre la calidad del producto terminado, realizando una evaluación química y sensorial. El ensayo se realizó en la temporada 2004-2005 en la provincia de Curicó, VII Región, Chile. Se analizaron aceites "coupages o multivarietales", procedentes de diferentes variedades de olivas. Los tratamientos evaluados fueron: $\mathrm{T}_{0}: 0 \%$ de adición de agua; $\mathrm{T}_{1}: 20 \%$ de adición de agua; $\mathrm{y}_{2}: 30 \%$ de adición de agua. En los tratamientos $\mathrm{T}_{1}$ y $\mathrm{T}_{2}$ existió una mejor calidad respecto al testigo $\left(\mathrm{T}_{0}\right)$. El tratamiento $\mathrm{T}_{2}$, con un índice global de calidad de 8,25 puntos, presentó la mejor calidad, dado por su mayor puntuación organoléptica y bajos índices químicos, a diferencia del tratamiento $\mathrm{T}_{0}$, que obtuvo un valor de 6,34 puntos, basándose en la reglamentación vigente (CE N ${ }^{\circ}$ 1989/03, la norma COI Res4/75-IV/96 y la norma NCh107of2001 (INN, 2001)).
\end{abstract}

Palabras clave: Aceite de oliva (Olea europaea L.), calidad, evaluación química-sensorial.

\begin{abstract}
The extra virgin olive oil is extracted mechanically from the olive fruit (Olea europaea L.) by methods of maturation, beating and centrifugation, adding water with the purpose of facilitating the extraction of the oil contained in the pulp of the fruit, and it must have a smaller or equal acidity to $0.8 \%$ expressed in oleic acid and one smaller or equal organoleptic score to 6.5 points, thus conserving valuable poliphenolic compounds of the original fruit. That grants a great quality to it, in addition to an excellent taste and aroma, which are transmitted in its bitterness and sharpness. Thus it is necessary to determine the quality of the national oil. The present study had the objective of evaluating the effect of the water addition in the elaboration process, on the quality of the finished product, making a chemical and sensorial evaluation. The test was made in the season 2004-2005 in the province of Curico, $7^{\text {th }}$ Region, Chile. Coupage or multivarietal oils were analyzed, coming from different varieties from olives. The evaluation treatments were: $T_{0}: 0 \%$ of water addition; $T_{1}: 20 \%$ of water addition; and $T_{2}: 30 \%$ of water addition.

In the treatments $T_{1}$ and $T_{2}$, it had a better quality in relation to the control $\left(T_{0}\right)$. The treatment $T_{2}$, with a global index of quality of 8.25 points, presented the best quality, given by a higher organoleptic punctuation and low chemical indexes; differing from treatment $T_{0}$, that obtained a value of 6.34 points, based on the current regulation (CE $N^{\circ} 1989 / 03$, the regulation COI Res-4/75IV/96 and the national regulation NCh107of2001 (INN, 2001)).
\end{abstract}

Key words: Olive oil (Olea europaea L.), quality, chemistry-sensorial evaluation.

1 Universidad Católica del Maule, Facultad de Ciencias Agrarias y Forestales, Departamento de Ciencias Agrarias, Casilla 7-D, Carmen 684, Curicó. E-mail: nloyola@ucm.cl

Fecha de Recepción: 07 Noviembre 2006

Fecha de Aceptación: 22 Febrero 2007 


\section{INTRODUCCIÓN}

\section{ANTECEDENTES GENERALES}

El aceite virgen de oliva es el zumo o jugo oleoso, extraído mecánicamente del fruto del olivo (Olea europaea L.), por procesos de molturación, batido y centrifugación, permitiendo conservar valiosos compuestos polifenólicos, que le otorgan un gran valor alimenticio, medicinal, cosmético, además de un agradable gusto y aroma (COI, 1991).

La composición química y cualidades organolépticas del fruto son muy diferentes al de otras drupas, ya que posee una baja concentración de azúcar que asciende de $2,5 \%$ a $6 \%$, además de una alta cantidad de sustancias grasas como; ácido oleico (ácido graso monoinsaturado), tocoferoles (vitamina E) y polifenoles como la oleuropeína (sustancia amarga) y que le confieren características muy particulares de amargor y picor $^{1}$, otorgándole un gran valor alimenticio y medicinal, en la prevención de enfermedades cardiovasculares, arteriosclerosis, reumatismo, artritis y otras dolencias, como también cosmético, además de un excelente gusto y aroma (Martínez de Victoria y Mañas, 2004).

El aceite de oliva está compuesto de una "fracción saponificable", constituida principalmente por triglicéridos (glicerol y ácidos grasos libres), y que está dominado por los ácidos: Oleico, palmítico, linoleico y esteárico, con una participación de un $55 \%$ a $83 \%, 7,5 \%$ a $20 \%, 3,5 \%$ a $21 \%$ y $0,5 \%$ a $5 \%$, respectivamente (COI, 1991); otra "fracción insaponificable", compuesta por hidrocarburos, alcoholes triterpénicos y alifáticos, esteroles y sustancias volátiles; "trazas metálicas" como el $\mathrm{Cu}, \mathrm{Fe}, \mathrm{Mn}$ y $\mathrm{Pb}$; además de "polifenoles", que son solubles en agua, por lo cual en el proceso de elaboración tienden a pasar a los residuos líquidos no oleosos, aunque una parte queda retenida en el aceite, su importancia radica en que tiene actividad antioxidante (Frías et al., 1999).

Los tópicos antes mencionados engloban el concepto de calidad que según la Organización Internacional de Normalización en su norma ISO 9000: 2000, define como el conjunto de características de un producto, un proceso o un servicio que le confiere la aptitud para satisfacer necesidades expresas o implícitas (Sin autor (a), 2004).

1 Sin autor (a), 2004.
Por estas razones la determinación de la calidad del aceite de oliva, a diferencia de otros productos alimenticios, debe ser analizada y cuantificada a través de algún índice o parámetro, como lo define la normativa mediante una evaluación química y sensorial (Sin autor (a), 2004), lo cual, al igual que otros productos alimenticios, es una herramienta bastante utilizada tanto por el sector elaborador como comercial, con el objetivo de obtener información sobre las características organolépticas percibidas por los consumidores, dado por el grado de aceptabilidad de éstos, debido a lo cual la (UE) y el Consejo Oleícola Internacional (COI) han establecido parámetros y normativas de calidad definidas en el reglamento CE $\mathrm{N}^{\circ}$ 2568/91, modificado por el CE N ${ }^{\circ} 1989 / 03$ del 6 de noviembre del 2003 (Uceda et al., 2004), así como la normativa del COI Res-4/75-IV/96 del 20 de noviembre de $1996^{2}$, las cuales clasifican a los aceites de oliva en categorías: Extravirgen, virgen fino, virgen corriente y lampante, de acuerdo a su calidad y en función de sus características fisicoquímicas y sensoriales, estableciendo así los procedimientos oficiales a seguir para cada determinación.

\section{HIPÓTESIS}

El agua aplicada en la fase de centrifugación horizontal del proceso de elaboración de aceite de oliva extravirgen, ejercería un efecto sobre la calidad de éste, permitiendo la obtención de un aceite con mejores características organolépticas.

\section{OBJETIVO GENERAL}

Determinar un Índice Global de Calidad (IGC) del aceite de oliva extravirgen, para cada una de las muestras evaluadas, correspondientes a dos líneas de aceites de origen nacional y una importada.

\section{OBJETIVOS ESPECÍFICOS}

Evaluar en forma química la calidad del aceite de oliva, para ser considerada como categoría extravirgen.

Medir las características organolépticas del aceite de oliva extravirgen, mediante cartillas de

2 Romero y Tous, 2005. 
evaluación sensorial, para obtener una puntuación organoléptica.

Medir la calidad del aceite de oliva extravirgen nacional, versus otro importado, según el Î́ndice Global de Calidad, para establecer sus diferencias.

\section{MATERIALES Y MÉTODOS}

El ensayo se realizó en el primer semestre del año 2005 en el laboratorio de ciencias de la Universidad Católica del Maule, ubicado en la ciudad de Curicó y en el laboratorio de microbiología de la misma Universidad en la ciudad de Talca, Séptima Región, Chile. Se analizó la calidad de 3 líneas de aceites de oliva extravirgen multivarietal tipo coupages existentes en el mercado, una de ellas importada y las otras dos de origen nacional, realizando una evaluación químico-analítica y sensorial. Las líneas nacionales se elaboraron entre el 12 de abril y el 5 de junio del 2004 en una planta olivícola, ubicada en la Séptima Región ( $35^{\circ} 02^{\prime}$ lat S y $71^{\circ} 25^{\prime}$ long O), Chile.

Para la elaboración de los aceites, tanto nacionales como para el importado se utilizaron cultivares tales como Frantorio, Coratina, Arbequina, Empeltre y Leccino, recolectados con un índice de madurez de cosecha por cambio de color o envero entre un $80 \%$ y $100 \%$ de área total coloreada.

El aceite se obtuvo sometiendo los frutos a procesos de molturación, batido y centrifugación en un sistema decanter, que utiliza un decantador centrífugo horizontal, permitiendo la separación de los sólidos u orujo, el agua de vegetación o alpechín y el aceite, formando anillos concéntricos, en función de su densidad, gracias a la acción de la fuerza centrífuga.

Posteriormente las líneas de aceite nacional, al igual que el aceite importado se almacenaron en estanques de acero inoxidable, por un tiempo de 5 meses, produciéndose decantación natural de borra, debiendo realizar 2 trasiegos cada 30 días y el tercero a los 90 días, periodo tras el cual se realizó el embotellado del producto final.

\section{DISEÑO EXPERIMENTAL}

Se evaluaron 2 tratamientos, al tratamiento $1\left(\mathrm{~T}_{1}\right)$ se aplicó un $20 \%$ de agua en el proceso de centrifugado y al tratamiento $2\left(\mathrm{~T}_{2}\right)$ un $30 \%$. Tal aplicación de agua se realizó a través de un caudalímetro. Adicionalmente, se incluyó un tratamiento testigo $\left(\mathrm{T}_{0}\right)$ que corresponde al aceite importado. Se efectuaron 4 repeticiones por tratamiento utilizando un diseño completamente aleatorizado a un factor de efecto fijo. La unidad experimental correspondió a 1L de aceite contenido en una botella. Los resultados obtenidos fueron sometidos a análisis de varianza (ANDEVA) y en los casos que se detectaron diferencias significativas, se realizó la prueba de comparaciones múltiples mediante el test de Duncan $(\mathrm{p} \leq 0,05)$. Los tratamientos se encuentran ordenados en el Tabla 1.

Tabla 1

Porcentaje de agua aplicada antes del proceso de centrifugado en la elaboración de aceite de oliva extravirgen a cada uno de los tratamientos.

\begin{tabular}{|c|c|}
\hline Tratamiento & Dosis de agua \\
\hline $\mathrm{T}_{0}$ & $0 \%$ \\
\hline $\mathrm{T}_{1}$ & $20 \%$ \\
\hline $\mathrm{T}_{2}$ & $30 \%$ \\
\hline
\end{tabular}

Fuente: Propia, 2005.

\section{DETERMINACIÓN DEL ÍNDICE GLOBAL DE CALIDAD}

\section{Evaluación química}

Índice de acidez (IA)

Se determinó según el método establecido por la IUPAC $\mathrm{N}^{\circ}$ 2.201, 1979, para la determinación del índice de ácido (Gutiérrez, 1990; COI, 1991), norma ISO 660 (Madrid, 1994; y Madrid y Madrid, 2001), regido además por la norma Chilena NCh95. Of $1981^{8}$. Dicho análisis fue realizado en el laboratorio de ciencias básicas de la Universidad Católica del Maule, ubicada en Curicó.

\section{Reactivos}

Se utilizó; una solución etanólica de hidróxido potásico $0,1 \mathrm{~N}$, solución al $1 \%$ de fenolftaleína en

$8 \quad$ INN (a), 2005. 
metanol de $95 \% \mathrm{v} / \mathrm{v}$, mezcla de etanol-éter etílico en proporción 1:1, neutralizada exactamente con $\mathrm{KOH} 0,1 \mathrm{~N}$ etanólica, con fenolftaleína como indicador.

\section{Metodología}

Se pesaron 7,5 g de aceite en un matraz Erlenmeyer de $250 \mathrm{~mL}$, luego se procedió a disolverlos en $50 \mathrm{~mL}$ de la mezcla etanol-éter etílico. Posteriormente, se valoró agitando continuamente con $\mathrm{KOH} 0,1 \mathrm{~N}$ hasta observar el viraje del color del indicador, en que debía aparecer una coloración rosa de la fenolftaleína permaneciendo unos 10 segundos.

\section{Índice de peróxidos (IP)}

Se determinó conforme al método IUPAC $\mathrm{N}^{\mathrm{o}} 2.501,1979$, para la determinación del índice de peróxidos (Gutiérrez, 1990; COI, 1991), según la normativa ISO 3960 (Madrid y Madrid, 2001), regido además por la norma Chilena NCh105. Of $1980^{9}$. Dicho análisis fue realizado en el laboratorio de ciencias básicas de la Universidad Católica del Maule, ubicada en Curicó.

\section{Materiales}

Se utilizaron buretas de $50 \mathrm{~mL}$ graduadas en $0,1 \mathrm{~mL}$, matraces de $250 \mathrm{~mL}$, secos y exentos de oxígeno, para lo cual fue necesario barrer con nitrógeno, el cual fue cedido por la Viña Los Robles (Figura 1).

\section{Reactivos}

Para el análisis se utilizaron cloroformo y ácido acético glacial puro, exentos de oxígeno por barboteo, de una corriente de gas nitrógeno; solución acuosa saturada de yoduro de potasio; soluciones acuosas de tiosulfato sódico $0,002 \mathrm{~N}$, más una solución indicadora de almidón al $1 \%$ en agua destilada.

\section{Metodología}

Se tomó un matraz de $250 \mathrm{~mL}$ y se introdujeron rápidamente en él $2 \mathrm{~g}$ de aceite, posterior a lo cual

$9 \operatorname{INN}(\mathrm{b}), 2005$. se agregaron $10 \mathrm{~mL}$ de cloroformo, con el objetivo de disolver rápidamente el aceite por agitación, luego se agregaron $15 \mathrm{~mL}$ de ácido acético glacial y $1 \mathrm{~mL}$ de disolución acuosa saturada de yoduro potásico. Luego se cerro el matraz y se agitó durante 1 minuto, imprimiéndole un suave movimiento de agitación, para luego ser conservado en la oscuridad durante 5 minutos. Transcurrido ese tiempo se agregaron $75 \mathrm{~mL}$ de agua destilada, agitándolo con vigor para finalmente valorar el yodo liberado con una disolución de $0,002 \mathrm{~N}$.

\section{Absorbancia ultravioleta (K270)}

Se determinó conforme al método CAC/RM 26-70, volumen XI, de la Comisión del Codex Alimentarius (Gutiérrez, 1990) y según la norma COI/T.20/Doc. $\mathrm{N}^{\circ}$ 19/Rev.1 20014 , realizado en el laboratorio de microbiología de la Universidad Católica del Maule, ubicado en Talca.

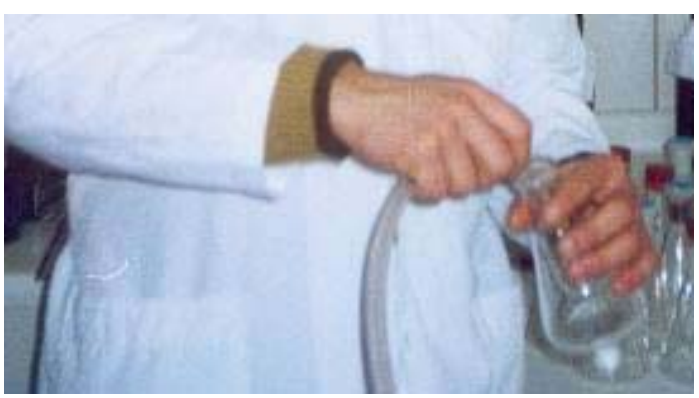

Figura 1. Inyección de gas nitrógeno en matraces de $250 \mathrm{~mL}$ preparados para el análisis de índice de peróxidos.

Fuente: Propia, 2005.

\section{Materiales}

Se utilizó un espectrofotómetro para medidas de extinción en el ultravioleta con valores comprendidos entre $190 \mathrm{~nm}$ y $900 \mathrm{~nm}$, con posibilidad de lectura para cada unidad nanométrica ${ }^{10}$. Cubeta de cuarzo, con tapadera, con paso óptico de $1 \mathrm{~cm} \mathrm{y}$ matraces aforados de $25 \mathrm{~mL}$ (Figura 2).

\section{Reactivos}

Ciclohexano de calidad para espectrofotometría; alúmina básica para cromatografía de

\footnotetext{
4 Madrid, A. y Madrid J., 2001.

10 Norambuena, 2005.
} 
columna, n-hexano para cromatografía; columna de cromatografía de $450 \mathrm{~mm}$ de longitud y $35 \mathrm{~mm}$ de diámetro, equipada con un tubo de reflujo de un diámetro de $10 \mathrm{~mm}$.

\section{Metodología}

Antes de su evaluación, el aceite fue sometido al horno a una temperatura de $30^{\circ} \mathrm{C}$; posteriormente se realizó una limpieza con papel filtro Watman 1 con la finalidad de trabajar con muestras perfectamente homogéneas y exentas de impurezas en suspensión.

De la muestra ya preparada se pesaron $0,25 \mathrm{~g}$ y se colocaron en un matraz aforado de $25 \mathrm{~mL}$; luego se completó con el ciclohexano hasta el enrase, y se homogeneizó aplicándole suaves y continuos movimientos circulares, logrando la disolución completa de la muestra, con lo cual se obtuvo una solución perfectamente clara y sin turbidez. Posteriormente, se llenó una cubeta de cuarzo con la solución obtenida y se midió el paso de la luz en la muestra a $270 \mathrm{~nm}$, usando como referencia el ciclohexano en forma pura como patrón de comparación.

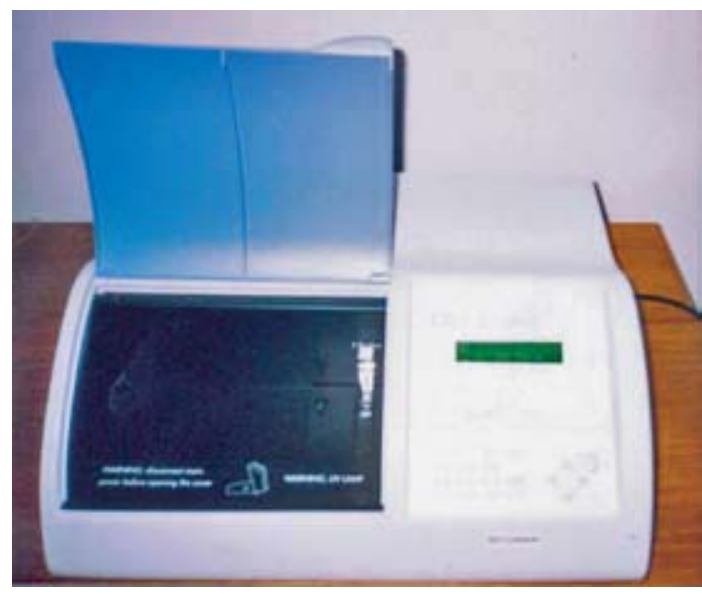

Figura 2. Espectrofotómetro ultravioleta para medir absorbancia de las muestras de aceite de oliva.

Fuente: Propia, 2005.

\section{Evaluación sensorial}

El objetivo de este análisis fue evaluar y cuantificar los atributos positivos y negativos del aceite de oliva, para la obtención de una puntuación organoléptica por parte de un grupo de catadores debidamente seleccionados y entrenados. El fundamento de este análisis se basa en el empleo de los sentidos olfato-gustativos y retronasales, y su interpretación expresada por el grado de aceptabilidad de los panelistas (Hurtado, 2003).

\section{Formación del panel de cata}

El análisis sensorial de aceites de oliva se realizó utilizando un panel de catadores seleccionados y entrenados para dicha evaluación según la norma COI T20/Doc.14 del 17 de noviembre de $1994^{3}$. La formación del panel de catadores se realizó en cuatro etapas básicas:

\section{Reclutamiento}

El reclutamiento de los candidatos se efectuó mediante cuestionarios y entrevistas. Tuvo por objeto conocer la personalidad de los candidatos y las características. Las exigencias de condiciones fisiológicas y psicológicas no son muy rigurosas, ya que cualquier persona puede desarrollar esta actividad, siendo los principales aspectos que se tomaron en cuenta; buena salud, interés personal y disposición de tiempo para el ensayo.

A continuación, se recopilaron datos para visualizar el grado de interés y motivación del candidato a panelista, así como su disponibilidad real de tiempo, para lo cual se le realizó la siguiente encuesta a cada uno de ellos:

La encuesta señaló las siguientes preguntas.

1. ¿Le gustaría colaborar en los trabajos de este tema?; sí o no.

2. ¿Considera que este ensayo puede ser importante para mejorar la calidad del aceite de oliva en nuestro país y el comercio internacional de éstos?; sí o no y por qué.

3. No olvide que en este ensayo debe probar aceites; ¿Le desagrada hacerlo?; sí o no.

4. ¿Le gustaría comparar su habilidad olfatogustativa con la de sus compañeros?; sí o no.

5. ¿Tiene tiempo disponible?

Con esta información se realizó la preselección, rechazando a los candidatos con poco interés en el ensayo, con poco tiempo disponible o incapaces para concretar sus ideas.

\footnotetext{
3 Madrid A., 1994.
} 


\section{Selección}

La selección se realizó con el objeto de elegir a los catadores más sensibles y de mayor capacidad discriminatoria, las pruebas se realizaron con muestras parecidas del punto de vista organoléptico al producto que se va a analizar posteriormente.

En una primera etapa, se realizaron evaluaciones de muestras de agua con azúcar, con sal, con jugo de limón, esencia de ají y vinagre, en diferentes concentraciones y tuvo por finalidad vislumbrar la sensibilidad e identificación de las muestras, por parte de los catadores, desde leve a intenso, dado por el sentido del gusto, tal como se aprecia en la Figura 3.

En una segunda etapa, se realizaron evaluaciones con muestras que están asociadas a los aromas y sabores típicos y más influyentes de los aceites de oliva, para lo cual se utilizaron preparados de pulpa de aceituna de mesa, manzana, caqui, almendra, nueces, tomate, hojas verdes de hortalizas y ají, disueltas en agua y a diferentes concentraciones, donde los catadores utilizaron primero el sentido del olfato y luego el gusto (Figura 4).
Estas evaluaciones tuvieron como objetivo identificar las distintas muestras familiarizando al catador con los principales atributos positivos y negativos, presentes en el aceite de oliva. Todos aquellos catadores que no lograron identificar las muestras fueron desechados del programa, por no contar con un grado mínimo de perceptibilidad.

\section{Entrenamiento}

Los objetivos de esta etapa fueron:

a) Familiarizar al catador con la metodología, respecto a las variantes olfato-gustativas.

b) Incrementar la habilidad individual, para conocer, identificar y cuantificar los atributos sensoriales.

c) Mejorar la sensibilidad y la memoria sensorial para conseguir juicios consistentes.

En este proceso se evaluaron sensaciones producidas por el aceite de oliva, tanto en lo que respecta a la intensidad de atributos positivos, tales como: Frutado a olivas, aroma a manzana, amargo, astrin-

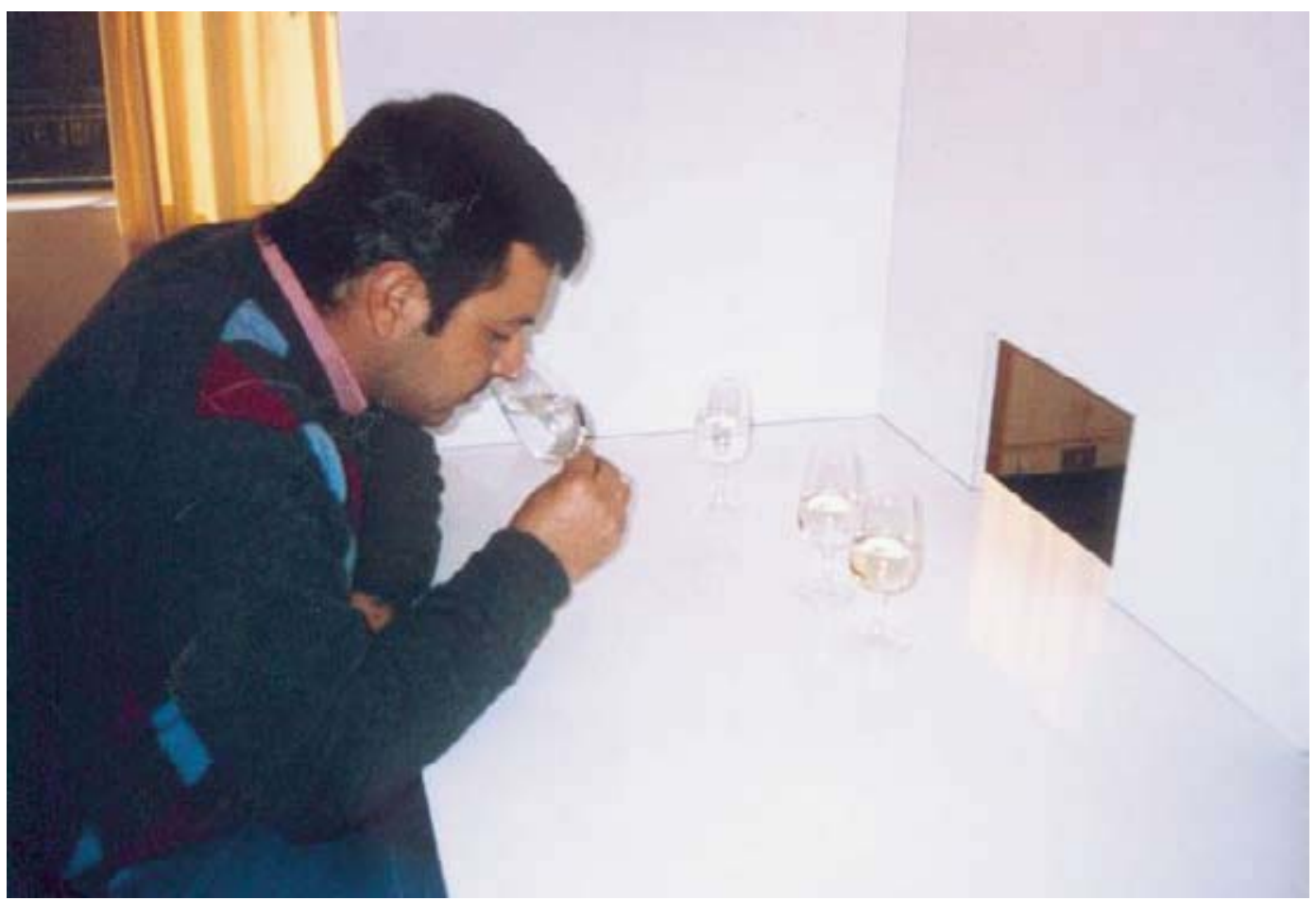

Figura 3. Pruebas preliminares de evaluación de los catadores para medir la percepción de los cuatro sabores elementales. Fuente: Propia, 2005. 


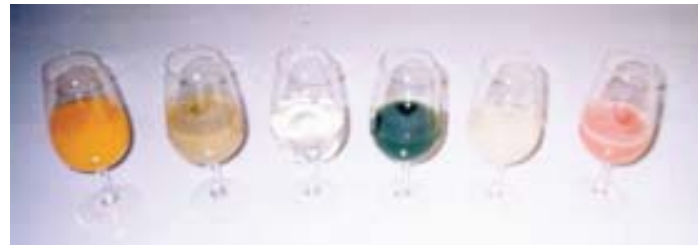

Figura 4. Instalación del set de pruebas preliminares de selección, para determinar el reconocimiento de las sensaciones más atractivas de las muestras por parte de los catadores.

Fuente: Propia, 2005.

gencia, picante, dulce y aroma a vegetales verdes, como también las posibles intensidades de defectos, tales como: Avinado-vinagre, moho-humedad, aroma y percepción de borras, atrojado y rancio.

El entrenamiento consistió en la degustación de aceites de oliva extravírgenes, de características similares a las que serían evaluadas con posterioridad. Se analizaron individualmente las muestras, contestando en una hoja de respuesta de características similares a la utilizada en la evaluación sensorial, en relación con la intensidad de cada atributo percibido por el catador en dicha muestra.

Los catadores después de haber analizado individualmente las muestras, y haber contestado la planilla de resultados, emitieron su juicio en forma verbal, en cuanto a la apreciación que tuvieron, comentando las calificaciones y dificultades encontradas en el proceso, con el objetivo de armonizar criterios y unificar opiniones. Este proceso se consideró eficaz para disponer de datos sensoriales exactos y precisos.

\section{Comprobación del nivel alcanzado}

Sobre la opinión de estos catadores ya entrenados, se tomaron las decisiones de importancia de la evaluación sensorial, razón por la cual los catadores fueron sometidos a comprobaciones para garantizar la fiabilidad de los resultados. Después de este proceso se contó con 12 catadores seleccionados y debidamente entrenados, para realizar la evaluación sensorial de las muestras de aceite de oliva a analizar.

Debido al cumplimiento de estas cuatro etapas básicas, además de un control individual permanente de cada individuo, permitió aumentar la eficacia del panel sensorial y la confianza en sus resultados.

\section{Procedimiento}

En este estudio se caracterizaron desde el punto de vista sensorial tres líneas de aceite de oliva ex- travirgen de origen nacional y extranjero, utilizando el método panel-test Reglamento CE N ${ }^{\circ} 756 / 2002$ Anexo XII y la norma COI/T20/Doc. No 15/Rev 1, con la finalidad de establecer sus fuentes de variación, a través de un puntaje organoléptico o puntuación final. La evaluación sensorial, también denominada cata, fue realizada en el laboratorio de ciencias básicas de la Universidad Católica del Maule, ubicada en Curicó.

\section{Materiales}

\section{Sala de cata}

La sala de cata cumplía con los requisitos de la norma UNE 87-004-79³, la cual especifica evitar condiciones ambientales que interfieran en la respuesta de los catadores, tales como; olores, ruidos y conversaciones entre panelistas. Además la norma establece que dicha evaluación debe realizarse en cabinas individuales e independientes, con paneles laterales, evitando así la comunicación de los panelistas y otorgándoles comodidad y privacidad. También las cabinas tenían una ventanilla para recibir las muestras. Asimismo, la sala de cata tuvo una adecuada luminosidad, tanto ambiental como individual y una temperatura de $25^{\circ} \mathrm{C}$ (Figura 5).

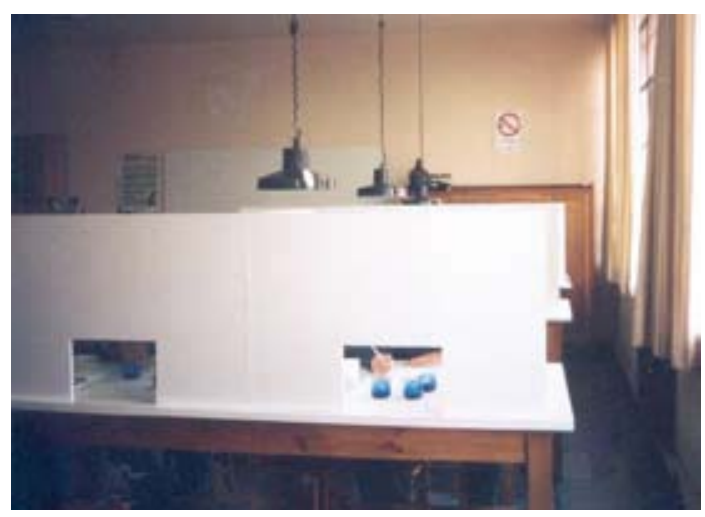

Figura 5. Sala de cata, con cabinas individuales e independientes.

Fuente: Propia, 2005.

\section{Copa para la degustación}

Para la degustación se utilizó una copa que cumplía con la norma COI/T.20/Doc. No 5 de 1996², 
que debe ser de vidrio azul cobalto, para que el color del aceite no influya en la decisión del panelista. La copa de degustación, mitad taza mitad copa, debe tener forma de tulipán para favorecer la concentración de aromas y facilitar su identificación. Las dimensiones de la copa de degustación son:

Capacidad total $130 \mathrm{~mL}+/-10 \mathrm{~mL}$ Altura total $60 \mathrm{~mm}+/-1 \mathrm{~mm}$ Diámetro de la boca .......................... $50 \mathrm{~mm}+/-1 \mathrm{~mm}$ Diámetro de la parte

más ancha. $70 \mathrm{~mm}+/-1 \mathrm{~mm}$ Diámetro de la base........................... $35 \mathrm{~mm}+/-1 \mathrm{~mm}$ Espesor de vidrio en las paredes laterales.... $35 \mathrm{~mm}+/-1 \mathrm{~mm}$ Espesor de vidrio en el fondo $1,5 \mathrm{~mm}+/-0,2 \mathrm{~mm}$ $5 \mathrm{~mm}+/-1 \mathrm{~mm}$

\section{Otros materiales para la evaluación sensorial}

Al momento de realizar la evaluación sensorial cada catador debió contar en su cabina con la copa con aceite cubierta con un vidrio reloj, además de los siguientes materiales: Aceite de oliva extravirgen, un platillo con cortes de manzana; un platillo con pan de molde integral; un vaso plástico con café recién hervido; lápiz pasta color azul; un vaso de agua; un resumidero; servilletas y una cartilla de respuestas para cada muestra de aceite.

\section{Metodología}

Para las condiciones del ensayo, el catador debió cumplir con ciertas normas de comportamiento, tales como: Abstención de fumar al menos 30 minutos antes del ensayo; no utilizar perfumes, cosmético o jabón aromático cuyo olor persista en el momento del ensayo; no ingerir ningún tipo de alimento, al menos una hora antes de la cata. En el caso que el panelista hubiese tenido problemas de salud, tales como sentido del gusto y del olfato afectados, debía comunicarlo oportunamente, con la finalidad de utilizar catadores de reserva.

Se citó a las 12 personas a las 09:00 A.M. y se tomó un tiempo de 15 minutos aclarando cualquier duda en cuanto a la realización de los ensayos, sin sugerir ningún tipo de opinión acerca de las muestras que pudiera interferir en su decisión.

\section{Operaciones previas}

Las copas contenían una cantidad de $15 \mathrm{~mL}$ de aceite, tapadas con un vidrio reloj y estaban sometidas a una temperatura de $28^{\circ} \mathrm{C}$ en una estufa, temperatura a la cual se favorecería una adecuada volatilización y concentración de los compuestos aromáticos del aceite, apreciando con mayor facilidad las cualidades organolépticas.

Cada una de las copas estaban codificadas con un código de tres letras elegidas al azar, ejemplo: AAC, las cuales al momento de la cata se sacaron de la estufa y se ubicaron en las respectivas cabinas, para su posterior evaluación como lo muestra la Figura 6.

A continuación, cada uno de los panelistas tomó ubicación en las cabinas, en orden y silencio, examinando si el material presentado estaba en orden y era el correcto. Posteriormente, se procedió a leer cuidadosamente las instrucciones contenidas en la hoja de puntuación, denominada hoja de perfil según la Norma CE No 796/2002 Anexo XII ${ }^{3}$, la cual se presenta en la Figura 7.

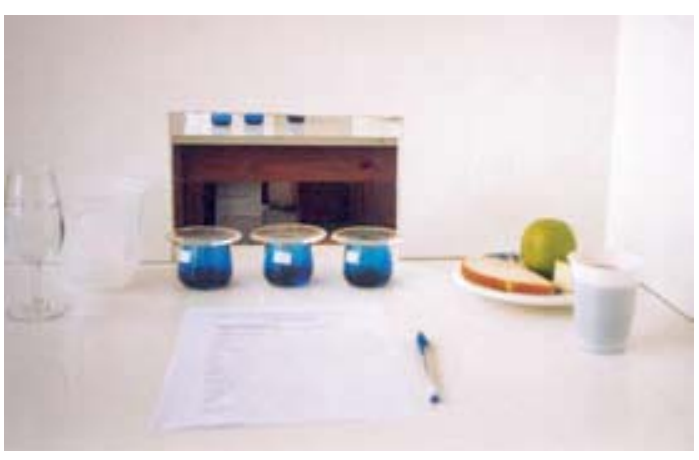

Figura 6. Cabina equipada para la cata de aceite de oliva extravirgen

Fuente: Propia, 2005.

En esta planilla de respuestas se utilizó el método de Análisis Descriptivo Cuantitativo (QDA), que mide cuantitativamente las características del aceite de oliva, sobre una escala no estructurada de $10 \mathrm{~cm}$ de longitud anclada en su origen, lo que permite comparar las intensidades de los atributos y proporcionar un medio para interpretar los resultados.

Como se aprecia en la Figura 14, en la parte izquierda de esta hoja de respuestas se incluyeron las percepciones sensoriales o atributos, más las características que suelen encontrarse con mayor frecuencia en el aceite de oliva; en el caso en que se encontraron otros estímulos que no correspondían con los calificativos enumerados, el catador 
Panel de Cata de Aceite de Oliva (Olea europaea L.) Extravirgen de Curicó

Sede oficial: Laboratorio de ciencias básicas de la Universidad Católica del Maule

Hoja de Valoración Sensorial

Norma CE No 796/2002

Tratamiento: Repetición: Muestra:
Código de identificación de la muestra:
Código de identificación del catador:
Fecha:

Atributos Positivos:

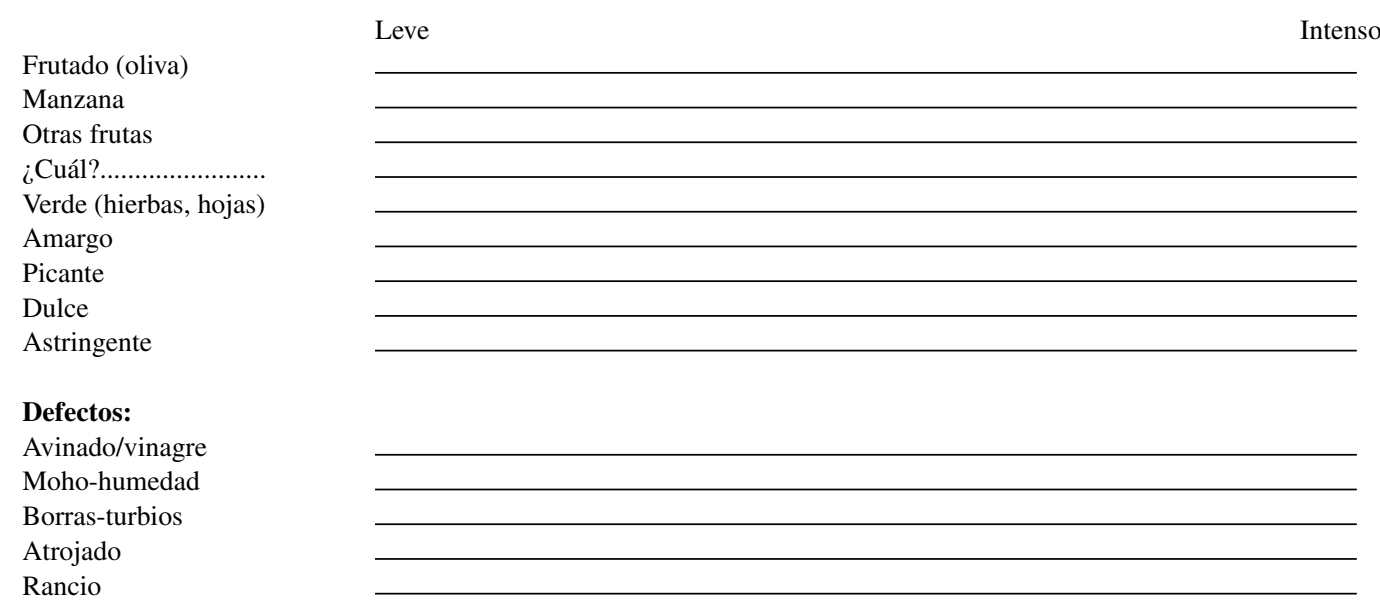

Observaciones:

Figura 7. Hoja de valoración sensorial para aceite de oliva extravirgen.

Fuente: Romero y Tous, 2005.

los anotó como observaciones. En la parte central de la hoja se encuentra una línea de respuesta que clasifica al atributo de leve a intenso, lo que debe ser valorado proporcionalmente a su intensidad, indicando éste con una raya en forma vertical en la línea correspondiente.

Para determinar la Puntuación Organoléptica se utilizó un modelo propuesto por el Profesor Rafael Gutiérrez en el año 1990.

\section{Fases de la cata}

\section{Fase olfativa}

El catador procedió a tomar la copa, manteniéndola cubierta con su vidrio reloj, la inclinó ligeramente, dando un giro total mojando lo más posible la superficie interior, luego se separó el vidrio reloj de la muestra y se procedió a su evaluación, identificando y cuantificando los aromas y su intensidad. El catador procedió a oler la muestra, haciendo inspiraciones suaves, lentas e intensas, hasta formarse un criterio del aceite a juzgar. Este periodo de olfatación no sobrepasó los 30 segundos.

\section{Fase gustativo-táctil}

El catador tomó un pequeño sorbo de la muestra correspondiente a unos $3 \mathrm{~mL}$ aproximadamente, distribuyendo el aceite por toda la cavidad bucal, desde la parte anterior de la boca y la lengua hasta los pilares del paladar y la garganta, insistiendo en que el aceite 
se extienda en cantidad suficiente y muy lentamente por la parte posterior de la lengua, concentrando la atención en el orden de aparición de los estímulos, analizando los atributos dulces en la superficie de la lengua, el amargo al final de la misma, el picante en la garganta, tras tragar el aceite y respirar para oxigenarlo y el astringente como sensación residual en la superficie de la lengua (Figura 8).

\section{Fase retronasal}

El catador realizó ejercicios de aspiraciones cortas y sucesivas del aire por la boca, para percibir información por vía retronasal. Tras ingerir el aceite, éste se calienta a la temperatura corporal, desprendiendo aromas volátiles por vía retronasal, permitiendo identificar aromas secundarios, confirmando los percibidos en la primera fase olfativa.

Posterior a la cata, y una vez contestada la planilla de evaluación correspondiente, se procedió a retirar la hoja de respuesta y la muestra evaluada. Entre la cata finalizada y la siguiente, se dio un tiempo de descanso, para evitar que el catador se viera afectado por fatiga o pérdida de sensibilidad, razón por la cual entre dos catas sucesivas el catador debió masticar un trozo de pan y/o manzana sin tragarlo, neutralizando así el sabor de la muestra catada, y luego depositar los restos en el escupidero, procediendo seguidamente a enjuagarse la boca con agua a temperatura ambiente, además para neutralizar el aroma anterior, debió oler café un par de veces. Una vez realizado este preámbulo, el catador se dispuso a evaluar la siguiente muestra de la misma forma y así sucesivamente hasta la última muestra de la sesión, respetando el orden y los tiempos asignados.

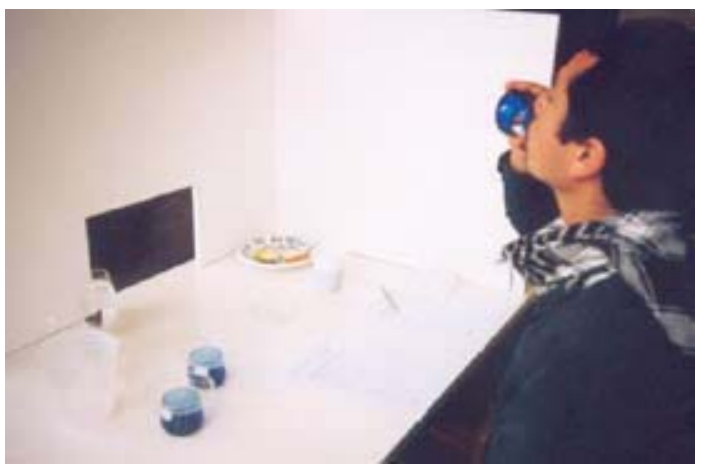

Figura 8. Fase gustativo-táctil de la evaluación sensorial de aceite de oliva.

Fuente: Propia, 2005.

\section{RESULTADOS Y DISCUSIÓN}

\section{ÍNDICE DE ACIDEZ (IA)}

Una vez agitada la muestra continuamente con $\mathrm{KOH} 0,1 \mathrm{~N}$ hasta viraje del color del indicador, comenzó a aparecer una coloración rosa-violeta debido a la fenolftaleína, permaneciendo alrededor de unos 10 segundos.

El índice de acidez se calculó según el método $\mathrm{N}^{\circ}$ 2.201, establecido por la IUPAC en el año 1979 (Gutiérrez, 1990), correspondiendo a un valor expresado como el porcentaje de ácido oleico, obteniéndose los resultados aquí descritos, apreciándose una disminución de dicho índice en los tratamientos $\mathrm{T}_{1}$ y $\mathrm{T}_{2}$, en relación con $\mathrm{T}_{0}$ (Figura 9).

Estos datos coinciden con lo reportado por Alba (2004), quien señala que con una mayor adición de agua al proceso de centrifugación se reduce el nivel de acidez.

Como resultado de la medición del índice de acidez, la aplicación de agua en el proceso de extracción del aceite de oliva fue efectiva para los tratamientos $\mathrm{T}_{1} \mathrm{y} \mathrm{T}_{2}$, lo que se confirma con los resultados obtenidos por Jiménez y Uceda (1995). De esta forma en el presente ensayo se facilitó una mayor extracción del agua de vegetación propia contenida en el aceite, lo que según Capogna y Alba (2003) evitaría una descomposición excesiva de los triglicéridos, conjuntamente con una disminución de los ácidos grasos libres, disminuyendo también la acidez.

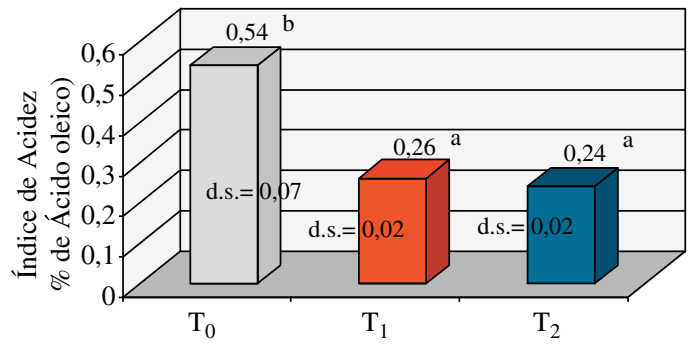

Promedios seguidos de igual letra, no presentan diferencia significativa al 5\% según el test de Duncan.

d.s. = desviación standard.

Tratamientos (\% de agua aplicada en la fase de centrifugado horizontal).

Figura 9. Índice de acidez del aceite de oliva, expresado en porcentaje de ácido oleico, tras la adición de agua en la fase de centrifugado horizontal. 
Los tres aceites evaluados desarrollaron una acidez menor a $0,54 \%$ de ácido oleico, comprobándose que su acidez es inferior en todos los casos a $0,8 \%$, según lo establecido por el reglamento CE $\mathrm{N}^{\circ} 1989 / 03$ (Uceda et al., 2004) y la normativa COI/T.20 (Sin autor (a), 2004). Todos los aceites analizados, con relación al índice de acidez evaluado en este ensayo, corresponderían a la categoría extravirgen.

El hecho de que los aceites nacionales, especialmente el tratamiento $\mathrm{T}_{2}$, presentaran una menor acidez, significa que se produjo un menor grado de descomposición de la molécula de triglicérido, evitando así que los ácidos grasos se separen del glicerol, proporcionándole una mayor estabilidad química al aceite de oliva, que será ratificado por los panelistas, según el parámetro moho-humedad en el capítulo correspondiente.

\section{ÍNDICE DE (IP)}

El índice de peróxidos de los aceites evaluados aumentó en mayor grado sólo en el tratamiento $\mathrm{T}_{0}$, tal como se observa en la Figura 10, alcanzando un valor promedio de 7,63 meq de $\mathrm{O} 2 / \mathrm{kg}$ de aceite, lo que a pesar de ser mayor a los expresados por los tratamientos $\mathrm{T}_{1} \mathrm{y} \mathrm{T}_{2}$, sigue correspondiendo a los valores aceptables, respecto de la categoría de aceite de oliva extravirgen (Uceda et al., 2004).

Se puede observar, además, una disminución en el índice de peróxidos para los tratamientos $\mathrm{T}_{1}$ y $\mathrm{T}_{2}$, lo que coincide con lo reportado por Alba (2004), quien señala que con la adición de agua al proceso de elaboración de aceite de oliva, específicamente en la fase de centrifugado, se reduce el índice de peróxidos, en comparación con un sistema de extracción en el cual no hay adición de agua al proceso.

Al romperse la molécula de triglicéridos en el proceso de elaboración del aceite de oliva, aumenta el porcentaje de ácidos grasos libres, elevando con ello la acidez y también se incrementarían los niveles de glicerol, produciéndose como consecuencia una oxidación espontánea de estos compuestos en presencia de $\mathrm{O} 2$, lo que se traduciría en un aumento del índice de peróxidos, con formación de compuestos denominados hiperóxidos, favoreciendo una descomposición y generando productos secundarios tales como aldehídos, ésteres, cetonas y alcoholes, que otorgan sabores catalogados como rancidez (Hurtado,
2003). Según Lehninger (1982), debido a la formación de estos compuestos secundarios, se genera un proceso de saponificación, debido a que se produce una hidrólisis alcalina de los ésteres de los ácidos grasos, que tiene como consecuencia la separación de fases, con producción de jabón; sales de ácidos grasos, situación que sucedió en las muestras ensayadas (Figura 11).

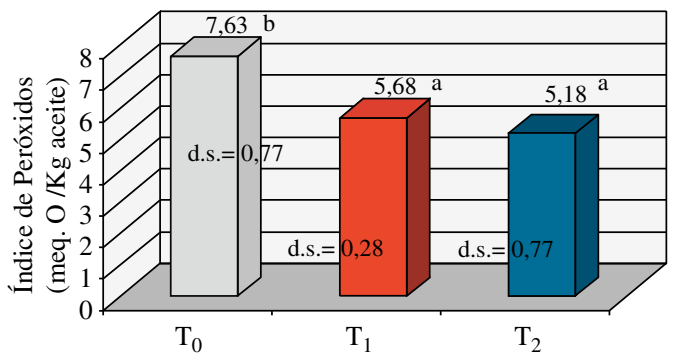

Promedios seguidos de igual letra, no presentan diferencia significativa al 5\%, según el test de Duncan. d.s. = desviación standard

Tratamientos (\% de agua aplicada en la fase de centrifugado horizontal).

Figura 10. Índice de peróxidos (meq $\mathrm{O} 2 / \mathrm{kg}$ de aceite), registrado al haber aplicado agua en la fase de centrifugación horizontal.

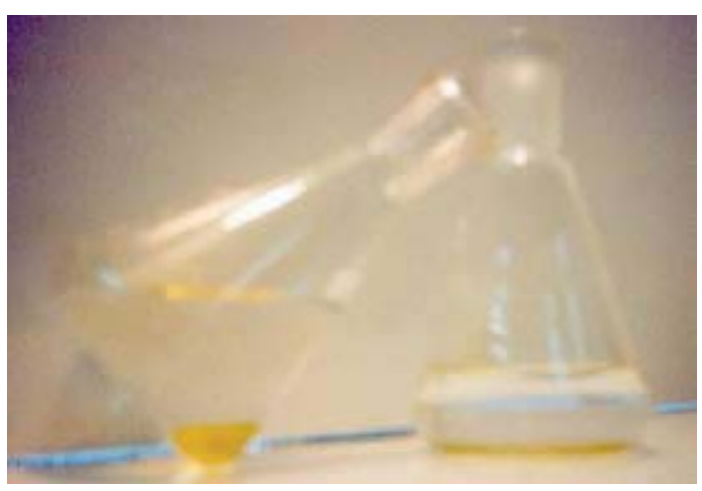

Figura 11. Muestra de aceite, después de realizado el índice de peróxidos.

Fuente: Propia, 2005.

Los resultados de este ensayo, en relación a la variación en los índices de peróxidos, asociados también a la presencia de un menor porcentaje de ácidos grasos libres, en aceites obtenidos con la aplicación de agua en la fase de centrifugado, en comparación con aquellos a los cuales no se les había aplicado agua, ratifican lo señalado por Alba (2004). 
Según Hurtado (2003), un incremento en el índice de peróxidos estaría muy asociado a los altos porcentajes de ácidos grasos libres, los cuales al oxidarse producirían una mayor oxidación del aceite, lo que vendría a fundamentar lo observado en el tratamiento $\mathrm{T}_{0}$ en comparación con los tratamientos $\mathrm{T}_{1} \mathrm{y}_{2}$.

\section{ABSORBANCIA ULTRAVIOLETA (K270)}

El tercer parámetro evaluado correspondió a la absorbancia de la muestra, medida a $270 \mathrm{~nm}$, que para el aceite de oliva categoría extravirgen debe tener un K270 menor o igual a 0,22 unidades de extinción específica (Sin autor (a), 2004). Según el análisis realizado en el presente ensayo, todas las muestras cumplían con esta normativa.

La absorbancia a $270 \mathrm{~nm}$ disminuyó considerablemente en los tratamientos $\mathrm{T}_{1}$ y $_{2}$, siendo ambos significativamente menores que el testigo $\left(\mathrm{T}_{0}\right)$, tal como se puede apreciar en la Figura 12.

Resultados similares a los obtenidos en este ensayo confirman las diferencias en las absorbancias de los aceites, tras la aplicación de agua en la fase de centrifugado (Capogna y Alba, 2003). Lo anterior está corroborado por Martínez de la Cuesta et al. (1995), quienes señalan que con la adición de agua en la fase de centrifugado horizontal se produce un fenómeno de autooxidación propia del aceite, asociado a una rancidez oxidativa causada por el estado de conservación y las modificaciones producidas en el proceso de elaboración.

La normativa COI/t.20/Doc.No 19/Rev. 1 2001, especifica realizar una nueva determinación de pureza del K270, cuando los valores límites de absorbancia sean superiores o mayores a 0,22 unidades de extinción específica (Uceda et al., 2004), lo que no fue necesario efectuar en este trabajo, dado la valoración obtenida.

\section{PUNTUACIÓN ORGANOLÉPTICA (PO)}

La adición de agua en la fase de centrifugado horizontal resultó ser efectiva sobre el grado de aceptabilidad por parte de los catadores en los tratamientos $\mathrm{T}_{1} \mathrm{y} \mathrm{T}_{2}$, en comparación con $\mathrm{T}_{0}$ en la evaluación sensorial bajo las condiciones ensayadas, produciéndose un aumento de la puntuación organoléptica, la cual puede observarse en la Figura 13.

Como se puede apreciar de la Figura 14, los 3 aceites evaluados cumplen con la exigencia que dicta

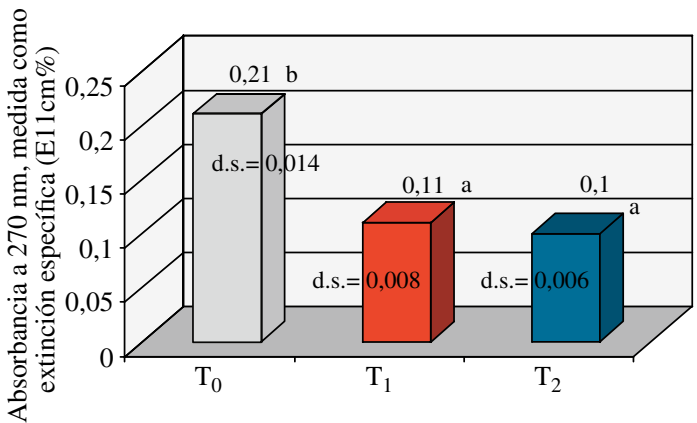

Promedios seguidos de igual letra, no presentan diferencia significativa al $5 \%$, según el test de Duncan. d.s. = desviación standard

Tratamientos (\% de agua aplicada en la fase de centrifugado horizontal)

Figura 12. Absorbancia medida a $270 \mathrm{~nm}$, tras la adición de agua en la fase de centrifugado horizontal.

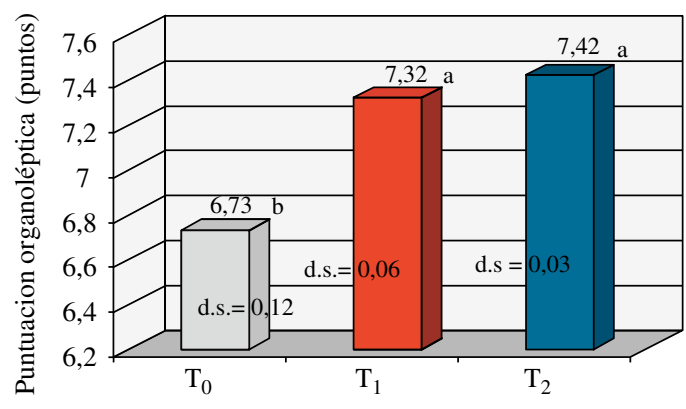

Promedios seguidos de igual letra, no presentan diferencia significativa al 5\%, según el test de Duncan.

d.s. = desviacion standard

Tratamientos (\% de agua aplicada en la fase de centrifugado horizontal).

Figura 13. Puntuación organoléptica, medida en puntos, de los aceites de oliva vírgenes, después de la aplicación de agua en la fase de centrifugado horizontal.

la norma en materia de puntuación organoléptica, con un puntaje mayor o igual a 6,5 puntos, correspondiendo a la categoría extravirgen (Uceda et al., 2004).

En la Tabla 2 se exponen los resultados finales de las intensidades de los atributos percibidos por los panelistas en la evaluación sensorial de los aceites analizados.

De los resultados obtenidos, se aprecia que el atributo frutado, que corresponde al sabor y aroma de olivas frescas, encontrado en los tratamientos $\mathrm{T}_{0}$, $\mathrm{T}_{1}$ y $\mathrm{T}_{2}$, correspondió a 2,$73 ; 3,10$ y 3,25 puntos de intensidad y, como todos son mayores que 
cero, clasifican dentro de la categoría extravirgen (Gutiérrez 1990; Sin autor (a), 2004).

Sin embargo, el tratamiento $\mathrm{T}_{0}$, a pesar de cumplir con las exigencias ya antes mencionadas en cuanto a puntuación organoléptica y atributo del tipo frutado, presentó defectos como moho-humedad y rancidez, los cuales fueron percibidos por el panel de cata, adjudicándole valores promedio de 1,24 y 1,50 puntos respectivamente, sobre el grado de intensidad de dichos defectos. Otros defectos consultados en la hoja de valoración sensorial (Figura 14), tales como: Avinado, borras y atrojado no fueron percibidos por el panel de cata, en ninguno de los tratamientos evaluados.

Tabla 2

Intensidades organolépticas, medidas en puntos, de los aceites evaluados

\begin{tabular}{|l|c|c|c|}
\hline \multicolumn{1}{|c|}{ Atributos } & \multicolumn{3}{c|}{ Intensidades } \\
\hline \multicolumn{1}{|c|}{ Positivos } & $\mathbf{T}_{\mathbf{0}}$ & $\mathbf{T}_{\mathbf{1}}$ & $\mathbf{T}_{\mathbf{2}}$ \\
\hline Frutado (F) & 2,73 & 3,10 & 3,25 \\
\hline Manzana (M) & 1,77 & 2,74 & 2,65 \\
\hline Verde (V) & 2,50 & 1,46 & 1,95 \\
\hline Amargo (A) & 3,05 & 1,40 & 1,09 \\
\hline Picante (P) & 2,87 & 1,28 & 1,03 \\
\hline Dulce (D) & 1,51 & 3,01 & 3,92 \\
\hline Astringencia (As) & 0,62 & 0,64 & 0,59 \\
\hline Defectos & 1,24 & 0,00 & 0,00 \\
\hline Moho/humedad (Mh) & 1,50 & 0,00 & 0,00 \\
\hline Rancio (R) & \multicolumn{4}{|l}{} \\
\hline
\end{tabular}

Los resultados obtenidos de la Tabla 2, en relación con la evaluación sensorial de las tres líneas de aceites evaluadas, su diferencia de intensidades y la presencia de defectos pueden apreciarse con mayor facilidad en la Figura 14.

La Figura 14 muestra las diferencias de los atributos en función de su intensidad, en los tres tratamientos evaluados y destaca la presencia de los defectos moho-humedad y rancidez sólo en el tratamiento $\mathrm{T}_{0}$, respecto de los tratamientos $\mathrm{T}_{1}$ y $\mathrm{T}_{2}$.

Si bien el tratamiento $\mathrm{T}_{0}$ cumplió con las exigencias químico-analíticas de calidad establecidas para los parámetros de acidez, peróxidos y absorbancia, el panel de cata pudo constatar la presencia de defectos en el aceite importado, en comparación con los aceites nacionales. Esta apreciación de parte de los panelistas se debió en gran medida a que los resultados de los valores químicos del aceite importado estaban muy cercanos al límite superior establecido según la normativa, presentando una diferencia considerable con lo registrado en los aceites nacionales, principalmente en lo que se refiere a los parámetros de acidez y peróxidos, lo cual también fue percibido por los catadores. Por lo señalado, se desprende del presente estudio que el aceite importado, correspondiente al tratamiento $\mathrm{T}_{0}$, no pertenece a la categoría extravirgen, pasando a la siguiente categoría: Virgen, la cual tolera defectos hasta intensidades de 2,5 puntos.

La presencia del defecto moho-humedad, debido principalmente a la acción fisicoquímica y biológica que sufren los frutos por agentes externos, tales como microorganismos contaminantes

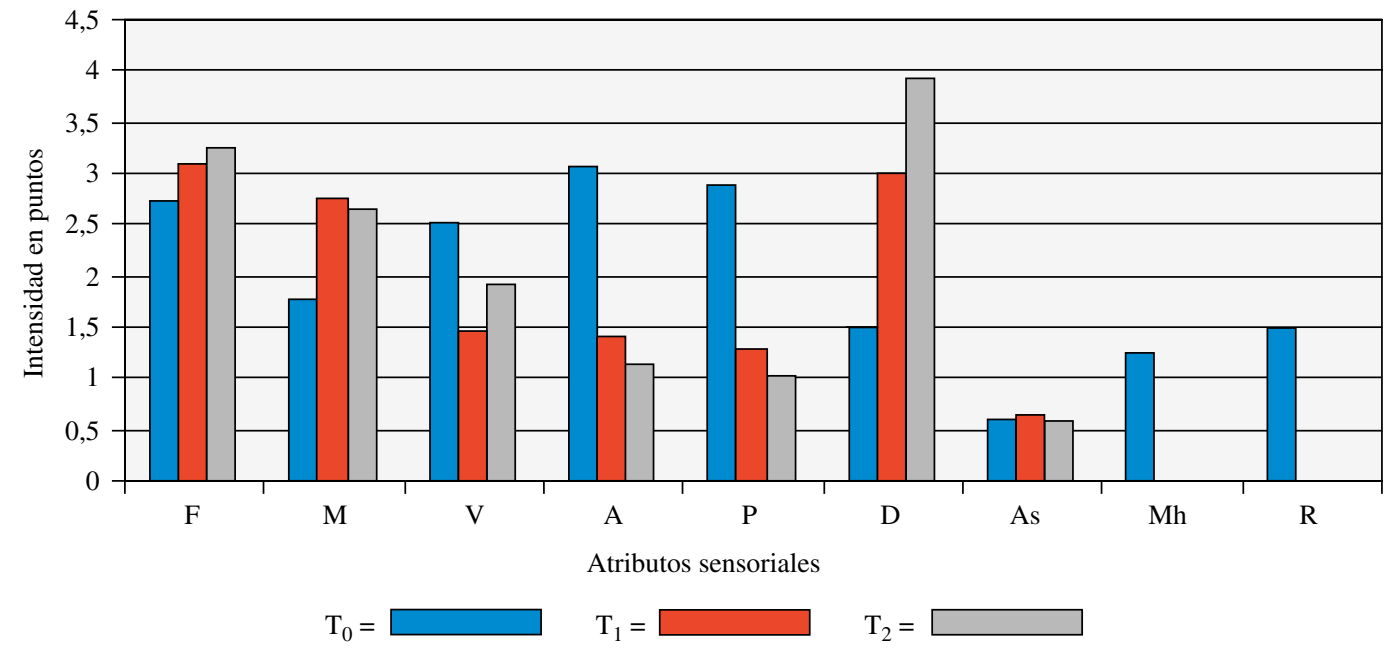

Figura 14. Intensidad de atributos positivos y defectos encontrados en los tratamientos evaluados. 
y excesivos tiempos de permanencia en bodega, antes de entrar a proceso, se traduce en un mayor índice de acidez, lo que fue detectado por el panel de cata, particularmente asociado al tratamiento $\mathrm{T}_{0}$, en relación con $\mathrm{T}_{1}$ y $\mathrm{T}_{2}$.

La rancidez detectada por los panelistas, como lo señala Martínez de la Cuesta et al. (1995), está asociada a los altos niveles de oxidación registrados y medidos (Figura 14), en que el aceite sufrió procesos de autooxidación como producto de la descomposición de los triglicéridos, generando aquellos defectos desagradables e irreversibles, afectando directamente la calidad del aceite.

\section{Intensidad de los atributos organolépticos percibidos por los panelistas}

En este sentido, las diferencias obtenidas en relación con las intensidades de cada uno de los atributos positivos: Frutado, manzana, verde, amargo, picante, dulce y astringente, se pueden observar con mayor facilidad en la Figura 15, en la cual se manifiestan los distintos perfiles sensoriales de los aceites evaluados $\left(\mathrm{T}_{0}, \mathrm{~T}_{1} \mathrm{y}\right.$ $\mathrm{T}_{2}$ ), según las intensidades percibidas por los panelistas.

Según Hurtado (2003), resulta relevante destacar en forma gráfica las características de los aceites según sus atributos positivos, fundamentalmente expresado mediante gráficos tipo "spider graph" o "estrellas sensoriales".

En el presente estudio se corrobora lo señalado por Jiménez et al. (1995), en el sentido que la intensidad de los atributos sensoriales, amargo y picante, se relacionan directamente con el frutado (Figura 15). Sin embargo, y también en concordancia con los mismos autores citados, aquellos atributos sensoriales se encontrarían inversamente relacionados con el atributo dulce (Figura 15), resultados que concuerdan también con lo informado por Sole (1997), en el sentido que el atributo dulce fue asociado con una baja intensidad de los atributos amargo y picante, lo que fue detectado por los panelistas como aceites más suaves y con un menor grado de picosidad.

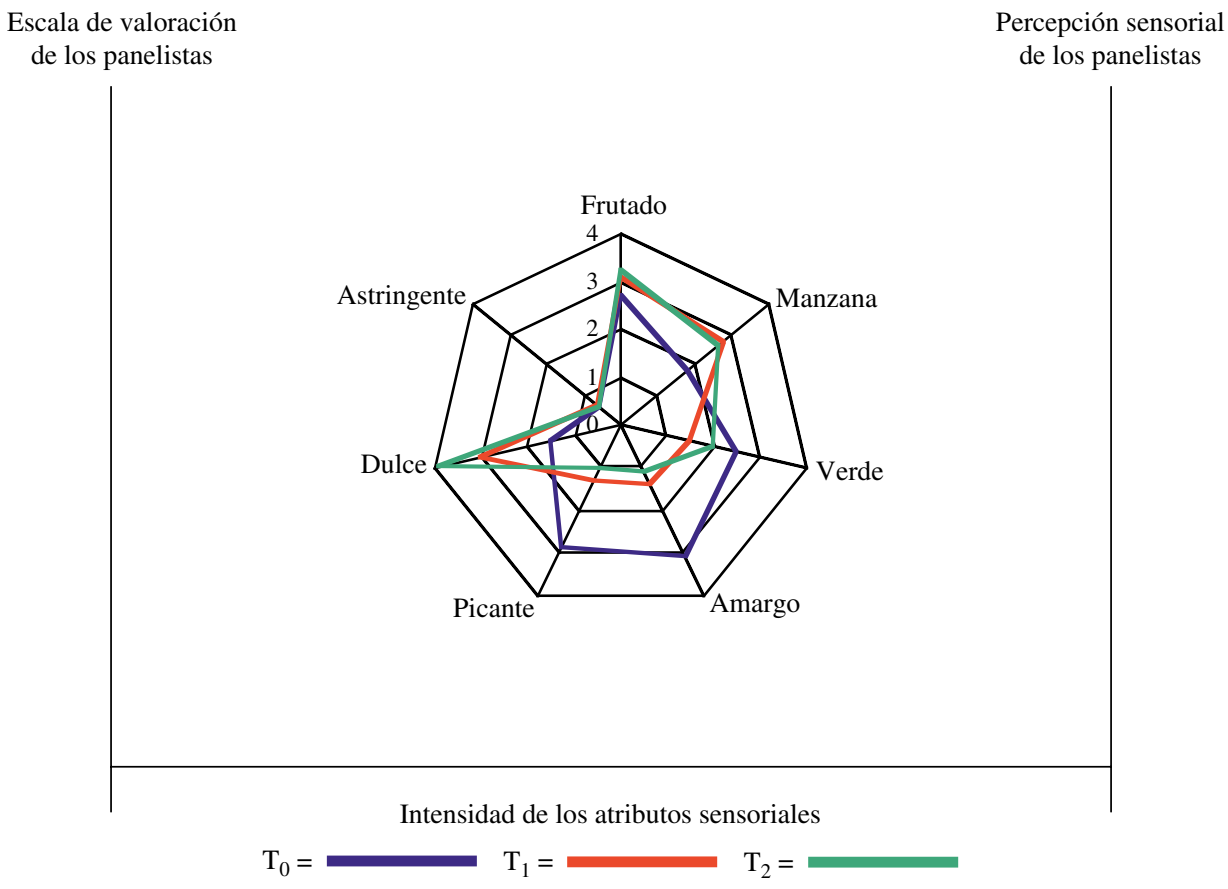

Manzana $=$ Sabor característico de este fruto, presente en el aceite de oliva .

Verde $=$ Aromas a hierbas y vegetales verdes recién cortados.

Figura 15. Expresión gráfica de los perfiles sensoriales de las tres líneas de aceites evaluadas con características organolépticas diferentes. 
A su vez, los tratamientos $\mathrm{T}_{1} \mathrm{y}_{2}$ presentaron una marcada influencia del atributo dulce, por sobre el amargo y el picante, sobre todo en el tratamiento $\mathrm{T}_{2}$, al cual se le adicionó un $30 \%$ de agua en el proceso de elaboración, lo que significó una menor intensidad del amargo y el picante, resultados que se pueden comparar con los informados por Jiménez y Uceda (1995), que presentaron una tendencia similar. La intensidad del atributo manzana se apreció con mayor influencia ante la disminución del amargo y el picante. El atributo verde presentó una intensidad más baja y el astringente, al igual que en el tratamiento $\mathrm{T}_{0}$ tuvo una baja participación (Figura 15). El comportamiento sensorial de los tratamientos $\mathrm{T}_{1}$ y $\mathrm{T}_{2}$ fue casi similar en la gran mayoría de los atributos evaluados.

De esta forma, se diferencian dos tipos de aceites con características organolépticas particulares; aquellos procedentes de un sistema de elaboración con adición de agua en la fase de centrifugado, correspondientes a los tratamientos $\mathrm{T}_{1} \mathrm{y} \mathrm{T}_{2}$, de procedencia nacional, y otro aceite sin adición de agua al proceso que correspondió al tratamiento $\mathrm{T}_{0}$ de procedencia extranjera.

$\mathrm{El}$ aceite importado, correspondiente al tratamiento $\mathrm{T}_{0}$, resultó ser un aceite frutoso, con una marcada influencia de amargor y picor, lo que se tradujo en un aceite bastante amargo, pesado y de gran viscosidad para el paladar de los panelistas. A su vez, el aceite correspondiente a los tratamientos $\mathrm{T}_{1}$ y $\mathrm{T}_{2}$ también resultó ser frutoso, con algunas notas de sabor a manzana, pero principalmente se trató de un aceite en que el atributo dulce presentó una mayor intensidad por sobre el amargo y el picante, lo cual lo hizo ser un aceite más liviano, suave y ligero, de acuerdo a la evaluación realizada por el panel de cata.

\section{INDICE GLOBAL DE CALIDAD (IGC)}

Referente al aceite de oliva extravirgen, el IGC se obtiene a partir de todos los parámetros anteriormente evaluados, tales como: IA, IP, K270, conjuntamente con la evaluación sensorial, asociada a la puntuación organoléptica.

En este sentido, los resultados del IGC para los aceites evaluados en este estudio se presentan en la Figura 16, donde se aprecia que el testigo $\left(\mathrm{T}_{0}\right)$ fue significativamente menor que los tratamientos en que se utilizó agua en la fase de centrifugado horizontal $\left(\mathrm{T}_{1}\right.$ y $\left.\mathrm{T}_{2}\right)$, y además estos no presentaron diferencias significativas entre ellos.

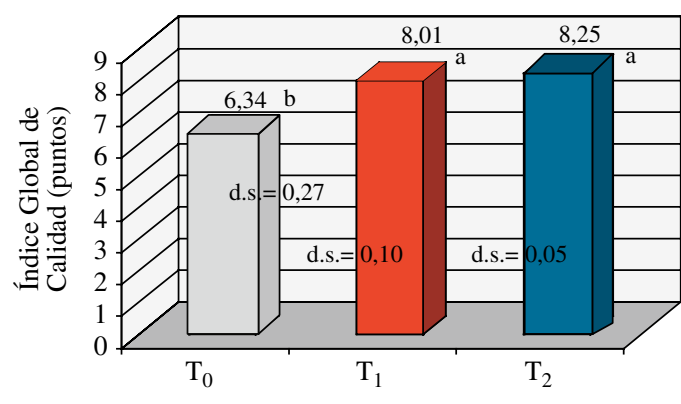

Promedios seguidos de igual letra, no presentan diferencia significativa al 5\%, según el test de Duncan. d.s. = desviación standard.

Figura 16. Determinación del índice global de calidad, tras la adición de agua en la fase de centrifugado horizontal.

La aplicación de agua en la fase de centrifugado horizontal, en los tratamientos $\mathrm{T}_{1}$ y $\mathrm{T}_{2}$, sería responsable del aumento en la calidad final del aceite, en comparación con el testigo $\left(\mathrm{T}_{0}\right)$ que no incluía este proceso. El tratamiento $\mathrm{T}_{2}$, correspondiente al aceite de oliva con un $30 \%$ de adición de agua, fue el que obtuvo la mayor puntuación con 8,25 puntos de un total de 10 , en la escala de puntuación final del concepto de calidad del reglamento COI (Sin autor, 1990; Uceda et al., 2004).

El IGC, en el aceite de oliva extravirgen, indica la calidad final, en una escala continua de 1 a 10 puntos, sin señalar un mínimo de puntaje, para clasificar a un aceite de oliva como extravirgen, razón por la cual los análisis químicos y sensoriales deben ser las herramientas necesarias para definir al aceite en esta categoría (Gutiérrez, 1990; Sin autor, 1990).

En relación con los análisis químicos efectuados en este ensayo, todos los aceites evaluados cumplieron con el reglamento CE No 1989/03 (Uceda et al., 2004), así como la normativa del COI Res-4/75-IV/96, siendo clasificados como extravírgenes.

Tras la evaluación sensorial, se determinó que los aceites nacionales correspondientes a los tratamientos $\mathrm{T}_{1}$ y $\mathrm{T}_{2}$ cumplieron con las normas CE 796/2002 Anexo XII y COI/T20Doc.N ${ }^{\circ}$ 15/ Rev1 (Hurtado, 2003), obteniendo una puntuación organoléptica mayor de 6,5 puntos y con ausencia de defectos, clasificándolos como extravirgen, situación que no sucedió en el aceite importado correspondiente al tratamiento $\mathrm{T}_{0}$. Respecto del tratamiento $\mathrm{T}_{0}$, los panelistas evaluaron al producto con más de 6,5 puntos, pero simultáneamente, el 
panel de cata detectó la presencia de defectos en el aceite evaluado correspondiendo a la manifestación de los defectos rancidez y moho-humedad, con una intensidad promedio de 1,37 puntos, lo cual significó que este aceite no correspondería a la categoría extravirgen, lo que concuerda con lo postulado por Jiménez y Uceda (1995).

Aun cuando el aceite importado cumplió con los requisitos de análisis químicos y puntuación organoléptica requerida por la COI (Uceda et al., 2004) para ser considerado dentro de la categoría extravirgen, lo que determinó su rechazo de parte del panel de catadores fue en rigor consecuencia de los defectos percibidos, debido principalmente a que aquellos fueron tal vez más sensibles y discriminatorios en cuanto a las diferencias existentes entre los aceites nacionales y el importado, en lo que respecta a la presencia de defectos.

Los panelistas, quienes representan probablemente al consumidor nacional, estarían más familiarizados a los aceites livianos y de una sensación de dulzor y suavidad parecidos a los aceites de consumo tradicional, como lo son los de maravilla y pepita de uva, características encontradas en los aceites de oliva locales, los cuales debido a la adición de agua en la fase de centrifugación horizontal, presentan una mayor pérdida de polifenoles que son compuestos responsables de un mayor grado de amargor y picor en los mismos.

Si bien hubo altos valores en el IA, tanto para el tratamiento $\mathrm{T}_{0}$ como $\mathrm{T}_{1} \mathrm{y} \mathrm{T}_{2}$, en todos los casos estuvieron dentro del rango aceptado por la norma $\mathrm{CE}$ № 1989/03. Sin embargo, Jiménez y Uceda (1995), respecto de la acidez, señalan que está relacionada con el aroma a moho-humedad detectado por los panelistas, el cual correspondería a un defecto generado en el aceite obtenido de frutos en los que se han desarrollado hongos y levaduras, a causa de haber permanecido mal almacenados y con humedad más de un día entre la cosecha y la entrada a proceso. El panel de cata detectó una fuerte intensidad de aquel defecto en el tratamiento $\mathrm{T}_{0}$, traduciéndose en un rechazo de las muestras analizadas, respecto de los tratamientos $\mathrm{T}_{1}$ y $\mathrm{T}_{2}$. En relación con el aceite nacional, a un menor IA se obtendría una mejor calidad organoléptica, expresada por una menor presencia de compuestos indeseables que alteren el sabor del producto final.

El índice de peróxidos estuvo muy relacionado con la rancidez de la muestra evaluada del tratamiento $\mathrm{T}_{0}$, percibida por los catadores, proveniente según lo señalado por Martínez de la Cuesta et al. (1995), de una autooxidación del aceite, debido a un prolongado contacto con el aire y un proceso de conservación inadecuado.

La absorbancia medida a $270 \mathrm{~nm}$ tuvo una relación positiva, tanto con los atributos sensoriales como con el grado de aceptación general de parte de los panelistas, ya que el panel de cata no detectó defectos sensoriales atribuibles a este parámetro evaluado, en ninguno de los tratamientos analizados.

En relación con la puntuación organoléptica, el hecho que el tratamiento $\mathrm{T}_{0}$, a pesar de presentar defectos, obtuviera una puntuación final mayor que 6,5 puntos, se debió a que en el cálculo de dicha puntuación intervienen tanto las intensidades de los atributos positivos amargor y picante como la de los defectos: Moho-humedad y rancidez. Lo que sucedió en este aceite fue que las intensidades de los atributos amargo y picante percibidos por los panelistas resultaron ser tan altas y tan marcadas con relación a los otros aceites evaluados, que la magnitud de los defectos no fue percibida en forma significativa, lo que se tradujo en la puntuación final. Por lo expuesto, el aceite importado cumple con la normativa CE N $1989 / 03$ (Uceda et al., 2004), que lo clasifica como extravirgen, a pesar de la discordancia encontrada en este ensayo, por la percepción de defectos de parte de los panelistas.

Con respecto a los atributos positivos, los aceites se han caracterizado por su carácter frutado, destacando el grado de intensidad de este atributo, independiente de la adición de agua en el proceso de centrifugado horizontal. Algunos autores como Sole (1997), afirman que el frutado es el atributo que más influye en la puntuación final de las muestras, lo que podría explicar que el tratamiento $\mathrm{T}_{0}$, a pesar de presentar defectos, obtuviera una puntuación final mayor que 6,5 puntos.

Todos los tratamientos evaluados: $\mathrm{T}_{0}, \mathrm{~T}_{1} \mathrm{y}$ $\mathrm{T}_{2}$, mostraron un equilibrio de los atributos verde, amargo y picante, la diferencia radica en que en los tratamientos $\mathrm{T}_{1} \mathrm{y} \mathrm{T}_{2}$, a diferencia del tratamiento $\mathrm{T}_{0}$, presentaron intensidades inferiores, debido principalmente a la adición de agua en la fase de centrifugado horizontal, donde se produce una pérdida de compuestos polifenólicos asociados a la presencia de éstos (Jiménez y Uceda, 1995). Según Jiménez et al. (1995), la sensación de suavidad del aceite en la boca, denominada dulzor, correspondiente al atributo dulce, se ha visto fuertemente influenciada 
por la adición de agua, situación que sucedió en los tratamientos $\mathrm{T}_{1}$ y $\mathrm{T}_{2}$.

El parámetro que más influyó en el resultado final del IGC fue la puntuación organoléptica, debido al grado de aceptabilidad general de parte de los panelistas, ya que en todos los tratamientos la puntuación final mantuvo un cierto equilibrio con el IGC, especialmente en el tratamiento $\mathrm{T}_{2}$, donde el aceite obtuvo una puntuación organoléptica de 7,42 puntos, que se reflejó claramente en la obtención de un IGC de 8,25 puntos, correspondiendo al valor más alto, en comparación con los otros tratamientos.

Con los resultados obtenidos en este ensayo, se plantea que la clasificación comercial del aceite de oliva extravirgen, no debería basarse sólo en la determinación de índices químicos, sino también en una valoración organoléptica con un panel de cata debidamente seleccionado y entrenado.

Lo anterior, dado que todos los tratamientos evaluados: $\mathrm{T}_{0}, \mathrm{~T}_{1}$ y $\mathrm{T}_{2}$, cumplieron con los requerimientos químico-analíticos de calidad, para ser

\section{LITERATURA CITADA}

ALBA, J. 2004. Elaboración del Aceite de Oliva Virgen. En: El Cultivo del Olivo. 5 Edición, Ediciones Mundi-Prensa. Madrid, España. 800 p.

BELTRÁN, G., UCEDA, M., HERMOSO, M. Y FRÍAS, L. 2004. La Maduración. En: El Cultivo del Olivo. $5^{\text {a }}$ Edición, Ediciones Mundi-Prensa. Madrid, España. 800 p.

CAPOGNA, D. Y ALBA, J. 2003. Influencia del sistema de extracción sobre algunos parámetros químico-físicos comerciales. En: Congreso Expoliva. Jaén. España. Resumen: 89-93.

COI. 1991. Colección de manuales prácticos. Mejora de la calidad del aceite de oliva. Madrid. España. 79 p.

FRÍAS, L., GARCÍA-ORTIZ,A., HERMOSO, M., JIMÉNEZ, A., LLAVERO, M., BERNARDIO, J., RUANO, M Y UCEDA, M. 1999. Analistas de Laboratorio de Almazara. Informaciones Técnicas 64/99. $2^{\text {a }}$ Edición. Edita Junta de Andalucía, Consejería de Agricultura y pesca. Sevilla, España. 124 p.

GUTIÉRREZ, R. 1990. Ciencia y Técnica: Metodología de evaluación de las cualidades organolépticas del aceite de oliva virgen. Madrid, España. Olivae (33): 18-23.

HURTADO, M. 2003. Un panel de cata para Chile. En: PRIMER ENCUENTRO Nacional de "Aceite de Oliva Futuro exportador del aceite de oliva Chileno". 25 de septiembre. Santiago, Chile. Centro de extensión "Los Almendros", Camino la pirámide 5625. Gobierno de Chile, Ministerio de Relaciones Exteriores, ProChile; ANPAO (Asociación Nacional de Productores de Aceite de Oliva). Resumen: 46-58.

INN (a). 2005. Norma Nacional NCh 95.Of1981. Cuerpos grasos de origen vegetal y animal, Método para determinar la acidez libre, índice de acidez y acidez mineral oficial. Disponible en: http://www.inn.cl. Consulta del 8 de abril de 2005. considerados como aceite de oliva extravirgen, en cuanto a los parámetros analizados: IA, IP y K270, en función del porcentaje de adición de agua al proceso de elaboración.

Además, con posterioridad a la adición de agua en el proceso de elaboración, la evaluación sensorial para todos los tratamientos analizados obtuvo una puntuación organoléptica mayor que 6,5 puntos, pero el tratamiento $\mathrm{T}_{0}$ presentó defectos como rancidez y moho-humedad, traduciéndose en un bajo grado de aceptabilidad de parte de los panelistas.

El presente trabajo, permitió diferenciar dos tipos de aceites, uno de origen importado $\left(\mathrm{T}_{0}\right)$, sin adición de agua en la fase de centrifugado horizontal, que presentó un IGC de 6,34 puntos, y otro de origen nacional correspondiente a los tratamientos $\mathrm{T}_{1} \mathrm{y} \mathrm{T}_{2}$, de los cuales el tratamiento $\mathrm{T}_{2}$, con un $30 \%$ de adición de agua, resultó ser él más efectivo, obteniendo un IGC de 8,25 puntos.

INN (b). 2005. Norma Nacional NCh 105.Of1980. Cuerpos grasos de origen vegetal y animal, Determinación del índice de peróxido oficial. Disponible en: http://www.inn. cl. Consulta del 8 de abril de 2005.

JIMÉNEZ, A. Y UCEDA, M. 1995. Características químicas y organolépticas del aceite de oliva virgen de la variedad Arbequina. I Simposio del olivo Arbequino en Cataluña, Borges Blanques. Madrid, España. Resumen: 145-148.

JIMÉNEZ, A., HERMOSO, M. Y UCEDA, M. 1995. Elaboración del aceite de oliva virgen mediante sistema continuo de dos fases: Influencia de las diferentes variables del proceso en algunos parámetros relacionados con la calidad del aceite. Madrid, España. Grasas y Aceites (46): 299-303.

LEHNINGER, A. 1982. Bioquímica: Las bases moleculares de la estructura y función celular. $2^{\text {a }}$ Edición, Ediciones Omega. Barcelona, España. 1117 p.

MADRID, A. 1994. Métodos Oficiales de Análisis de los Alimentos. Madrid, España. AMV Ediciones MundiPrensa $570 \mathrm{p}$.

MADRID, A. Y MADRID, J. 2001. Norma Comercial Internacional Aplicable a los Aceites de Oliva y Orujo de Aceituna. Madrid, España. AMV Ediciones MundiPrensa. $540 \mathrm{p}$.

MARTÍNEZ DE LA CUESTA, P.J., RUS MARTÍNEZ, E. Y GALDEANO CHAPARRO, M. 1995. Enranciamiento oxidativo de aceites vegetales en presencia de $\alpha$-tocoferol. Madrid, España. Grasas y Aceites (46): 349-353.

MARTÍNEZ DE VICTORIA, E. Y MAÑAS, M. 2004. El Aceite de Oliva en la Dieta y Salud Humanas. En: El Cultivo del Olivo. $5^{\text {a }}$ Edición, Ediciones Mundi-Prensa. Madrid, España. 800 p. 
NORAMBUENA, R. 2005. Comunicación Personal. Profesor de Microbiología, Universidad Católica del Maule. Curicó, Chile.

ROMERO, A. Y TOUS, J. 2005. Análisis Sensorial de Aceite Virgen de Oliva. Disponible en: http://www.percepdet.com/ cien12_03htm. Consulta del 4 de abril del 2005.

SIN AUTOR. 1990. Progresos del estudio de métodos modernos de análisis para los aceites de oliva y los aceites de orujo de aceituna. Madrid. España. Olivae (30): 11-15.
SIN AUTOR (a). 2004. Ciencia y tecnología: La calidad: importante objetivo del Consejo Oleícola Internacional. Madrid, España. Olivae (100): 30-34

SOLE, M.A. 1997. Los aceites virgen extra de la variedad Arbequina de Les Garrigues. Características organolépticas. Madrid, España. Frutícola Profesional (88): 125-129.

UCEDA, M., HERMOSO, M. Y AGUILERA, M. P. 2004. La Calidad del Aceite de Oliva. En: El Cultivo del Olivo. $5^{\mathrm{a}}$ Edición, Ediciones Mundi-Prensa. Madrid, España. 800 p. 